\title{
Designing A Remote Monitoring and Operating System for Base Transceiver Station Gensets
}

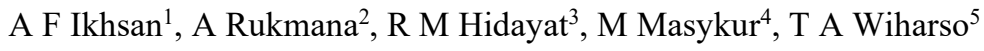 \\ Electrical Engineering Departement, Universitas Garut, J1. Raya Samarang 52A, Garut, \\ Indonesia.txfauzi@gmail.com
}

\begin{abstract}
Abstrack. Electricity plays a critical role in telecommunication business. Information transmission service infrastructure such as base transceiver stations (BTSes), base station controllers, and mobile switching centers must not lose electricity supply. Therefore, telecommunication enterprises have gensets as backup power supplies. However, these gensets are usually located at a point remote from the BTS, making it difficult for operators to monitor and operate them. This study designs an Arduino and Ethernet Shield remote monitoring and operating system for BTS gensets by utilizing a TCP/IP technology as communication protocols. Gensets are monitored using the likes of voltage sensor, current sensor and fuel sensor.
\end{abstract}

Keyword: Genset, Base Transceiver Station, Arduino, Ethernet Shield, Relay, TCP/IP

\section{Introduction}

The role that electricity plays is indispensable. Electricity is consumed in various scales, ranging from the small-scale household consumption such to the large-scale electricity consumptions such as those in big factories and companies, including telecommunication companies. In its daily operation, a telecommunication company uses BTSes that consume medium-scale electricity consumption, namely 100kVA. The BTSes usually have three electricity sources: electricity provided by the state electricity company PLN, gensets, and batteries. PLN electricity is the main energy source among the three. However, PLN electricity supply is sometimes not dependable. Therefore, BTSes have backup supplies from gensets and batteries during a PLN power outage. The problem is that these BTS gensets do not operate automatically. Failures in these gensets can cause telecommunication companies to fail in delivering their services. This is of course very detrimental to the company's best interests [1][2].

In an attempt to solve this problem, this study designs a remote monitoring and operating system for BTS gensets by utilizing a TCP/IP technology. The purpose is to help telecommunication companies with BTS genset operation and monitoring during PLN power outages. The genset operation will use Arduino, Ethernet module, TCP/IP network, and web service (HTTP) [3].

\section{Method}

The monitoring device designing is performed using a prototyping procedure as follows[4]

\subsection{Equipment preparation}

We identify some hardware and software required to implement the prototype of Remote Monitoring and Automation system of genset in a BTS.

The required hardware includes:

1. Sumura genset, single cylinder, air cooled, gasoline, 220 -volt output, 2500 watts

2. Fuel tank float sensor $10 \mathrm{k} \mathrm{Ohm}$

3. ATmega328 Arduino Uno

4. 4. DC Voltage Sensor 0 - 25 Volt coupled with the transformer to measure 220 Volt AC voltage 
5. LC Technology's ACS712 current sensors to be used as the electric current measuring instrument.

6. W5100 Ethernet Shield module

7. 2-channel relay module

\subsection{System Prototyping}

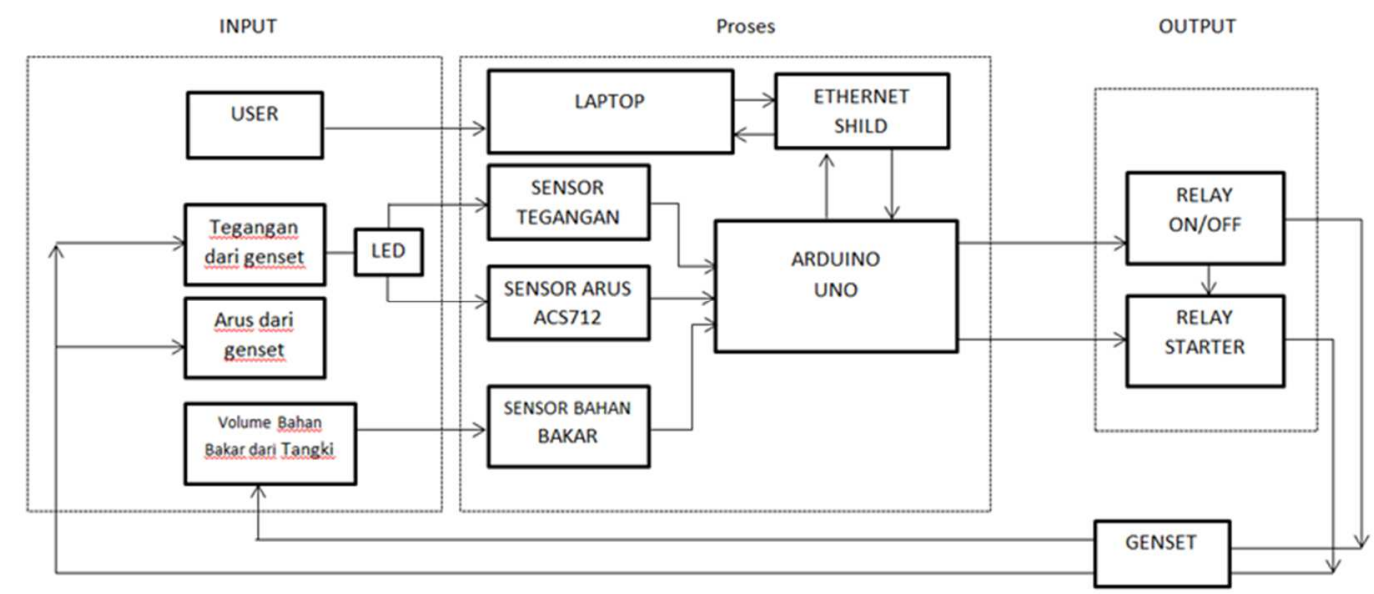

Figure 1 Block diagram

In order for this system to work properly, the user must first make sure that the device is connected to the genset ignition switch. Sensors will start working to provide input data. The fuel sensor will measure the amount of fuel available in the genset tank, the ACS712 current sensor will measure the genset output current, and the voltage sensor will measure the genset voltage. All measurement information will be transmitted to Arduino to process through Ethernet Shield into HTTP digital data with the help of LAN or TCP/IP protocol. The digital data will be displayed on a computer or a mobile device's web browser. Thorough the web browser, the user can monitor and turn the genset on and off.

Figure 2 illustrates the connection between the computer and the Ethernet Shield-installed device. 


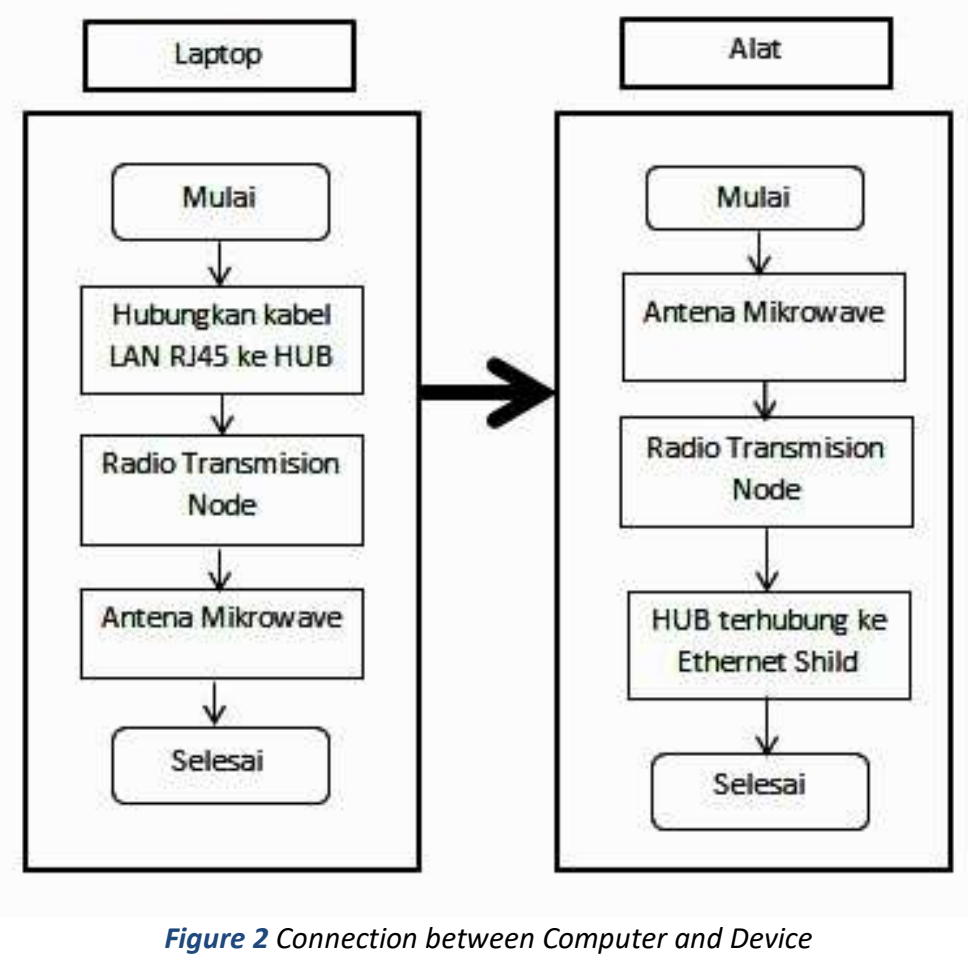

Figure 2 shows how the laptop is connected to the device. This connection is required to ensure the communication process to control the genset. First, the laptop is connected to the BTS HUB using LAN RJ45. The HUB is connected to the radio transmission node (RTN). The RTN connects one BTS to the other using a microwave antenna.

\section{Result and Analysis}

To make sure that the device works as expected, trials were made by turn the genset on and off using web interface on the laptop, which is connected to the system using LAN. Table 1 illustrate the ON/OFF button test.

\begin{tabular}{lll}
\hline NO & Button & Relay \\
& \\
\hline
\end{tabular}




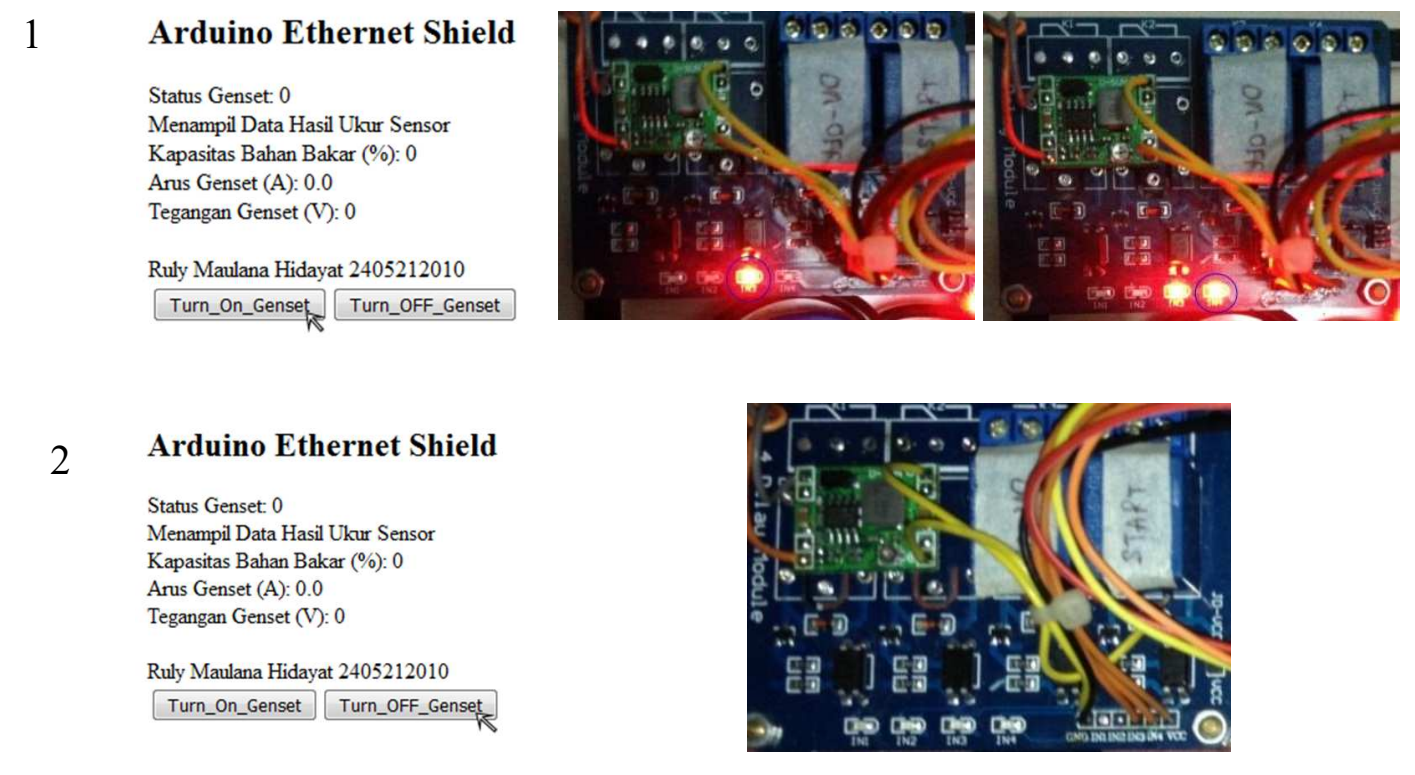

Table 1 Button Test

Table 1 shows that when the Turn_On_Genset button is pressed, the relay LED will be on. This indicates that the relay turns on the genset and its dynamo starter. When the Turn_OFF_genset button is pressed, the LED will be off and the relay turns off the genset. This indicate that command from computer successfully translated to digital state of the remote arduino.

Delay tests were performed to figure out how long it takes for the browser application to transmit the turn on/off command to the device.

\begin{tabular}{|c|c|c|}
\hline Button & Test & Delay Time \\
\hline \multirow{9}{*}{$\mathrm{ON}$} & 1 & $9.62 \mathrm{sec}$ \\
\hline & 2 & $10.51 \mathrm{sec}$ \\
\hline & 3 & $10.88 \mathrm{sec}$ \\
\hline & 4 & $9.25 \mathrm{sec}$ \\
\hline & 5 & $10.74 \mathrm{sec}$ \\
\hline & 6 & $9.68 \mathrm{sec}$ \\
\hline & 7 & $10.09 \mathrm{sec}$ \\
\hline & 8 & $9.48 \mathrm{sec}$ \\
\hline & 9 & $9.75 \mathrm{sec}$ \\
\hline
\end{tabular}




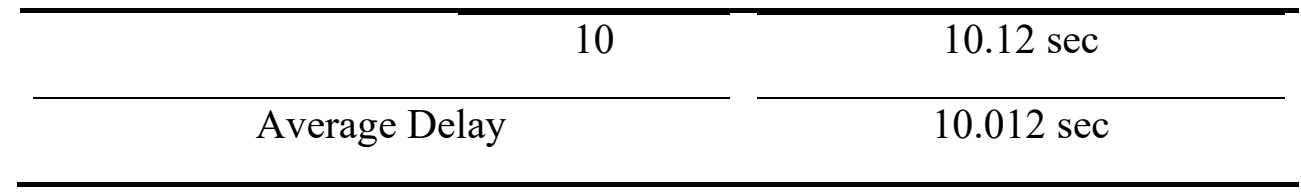

Table 2 Turn On Command Delay Test

Table 2 shows that on average, it takes 10.012 seconds for the interface to turn on the device. This delay comes from time to process or translating data format and delay of propagation. Unfornately we cannot distinguish them.

\section{Table 3}

\begin{tabular}{lll}
\hline Button & \multicolumn{1}{l}{ Test } & Delay Time \\
\cline { 2 - 3 } & 1 & $7.68 \mathrm{sec}$ \\
\hline \multirow{2}{*}{ OFF } & 2 & $7.09 \mathrm{sec}$ \\
& 3 & $7.48 \mathrm{sec}$ \\
& 4 & $8.75 \mathrm{sec}$ \\
& 5 & $8.12 \mathrm{sec}$ \\
& 6 & $8.08 \mathrm{sec}$ \\
& 7 & $7.54 \mathrm{sec}$ \\
& 8 & $7.99 \mathrm{sec}$ \\
& 9 & $8.07 \mathrm{sec}$ \\
& 10 & $7.69 \mathrm{sec}$ \\
& & $7.85 \mathrm{sec}$ \\
& &
\end{tabular}

Table 3 shows that on average, it takes 7.85 seconds for the interface to turn off the device.

Another test was performed to compare the transfer time form the laptop to the device using a LAN cable and form the laptop to the device using an intranet network (HUB). This test was done using a ping command. It was revealed that data transfer using a LAN cable took about $1 \mathrm{~ms}$, and that data transfer using an intranet network took approximately $63 \mathrm{~ms}$. The distance between the laptop and the BTS where the device was located was approximately $4.7 \mathrm{~km}$. this result is range of acceptance if we compare with time needed when doing manually. 


\section{Conclusion}

Based on the trial results, the designed device managed to turn the genset and off. The device can also monitor the genset from a remote point using a LAN connection to HUB and RTN between BTSes. On average, it takes 10.012 seconds for the device to turn on the genset and 7.85 to turn it off.

It takes about 15 minutes to operate the genset: 10 minutes spent by the operator to go to the nearest BTS, 2 minutes to turn on the laptop, 1 minute to connect the LAN to the HUB, and 2 minutes to enter the IP address on the web interface. It takes 24 watts for the device to start up and 18 watts when it is on standby mode. When all sensors are working, the device requires 28.8 watts.

In the Future we can adding location based sevice with GPS module and added much monitoring and controlling feature for BTS.

\section{Acknowledgement}

This publication is made possible by the support of Universitas Garut, Indonesia.

\section{References}

[1] T. Bhasin, "Reduction of Power Consumption at BTS using Fuzzy based Hierarchical System," pp. 42-48, 2013.

[2] C. Lubritto et al., "Energy and environmental aspects of mobile communication systems," Energy, 2011, doi: 10.1016/j.energy.2010.11.039.

[3] et al., "IOT Based Home Automation Using Arduino and ESP8266," Int. J. Comput. Sci. Eng., vol. 6, no. 4, pp. 267-270, 2018, doi: 10.26438/ijcse/v6i4.267270.

[4] A. Rosa, "Rekayasa Perangkat Lunak," 2013. . 